\title{
A case of campomelic dysplasia causing a pathological fracture
}

\author{
Biplab Maji ${ }^{1}$, Apurba Ghosh ${ }^{2}$, Kakali Roy $^{1}$, Akash Bhutura ${ }^{1}$
}

Sri Lanka Journal of Child Health, 2014; 43(4): 242-243

(Key words: Campomelic dysplasia; pathological fracture)

\section{Case report}

A 67 day old baby boy, presenting with hypotonia and respiratory distress, had abnormal mobility of the left lower leg for past15 days following gentle manipulation of leg while dressing the baby at home. On $\mathrm{x}$ - ray he had a fracture of the left tibia with normal callus formation (Figure 1).

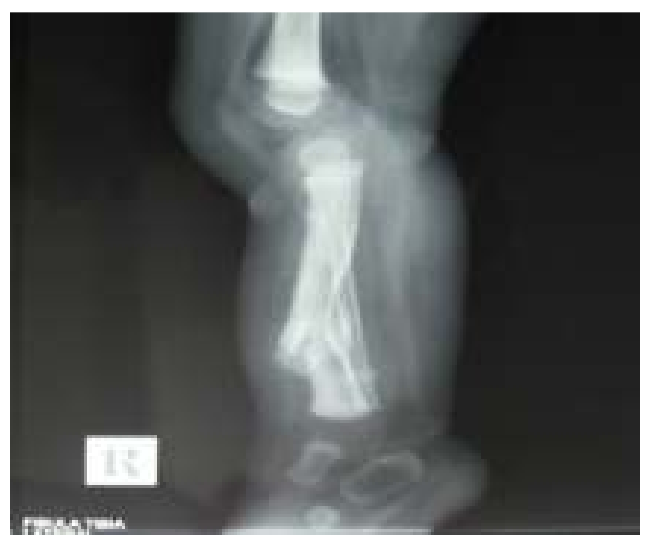

Figure 1: Fracture of left tibia

This $4 \mathrm{~kg}$ baby boy was delivered at 37 weeks from a second gravida mother by caesarean section and developed respiratory distress just after birth. He had macrocephaly, large forehead, low set ears, flat nasal bridge, cleft palate, small jaw, short bowed upper extremities, small deformed thoracic cavity, short stature $(42 \mathrm{~cm},<3$ rd percentile), a webbed short neck and normal male genitalia (Figure 2).

Radiographs showed bowed humerus, radius and ulna of both upper limbs and a deformed chest cavity with 11 pairs of ribs (Figures $3 \& 4$ ). Mother was not exposed to medications or radiation during pregnancy and there was no family history of skeletal abnormalities or congenital malformations. Baby had a male karyotype 46, XY. A diagnosis of campomelic dysplasia was made on the basis of clinical and radiological findings.

${ }^{1}$ Post Graduate Trainee, ${ }^{2}$ Professor and Director, Institute of Child Health, 11 Biresh Guha Street, Kolkata-700017, India

(Received on 12 September 2013: Accepted after revision on 25 October 2013)

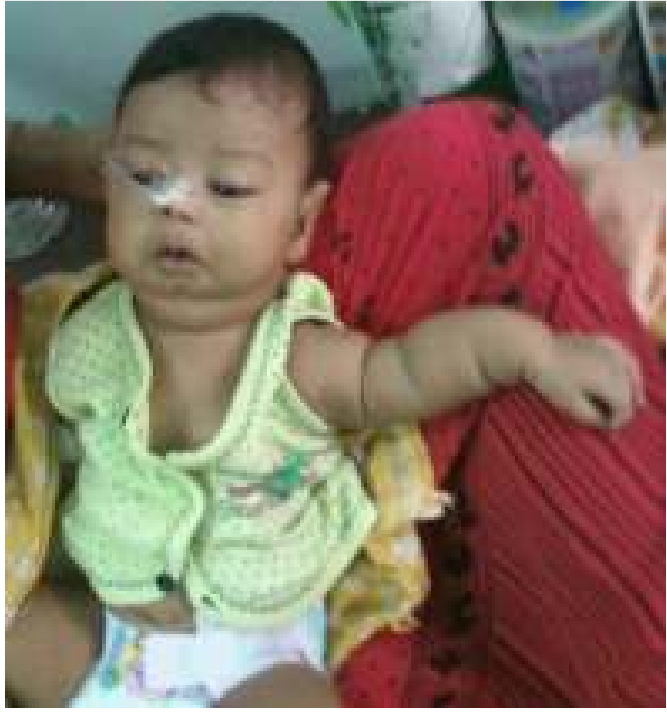

Figure 2: showing bowed upper extremity, small jaw and low set ears

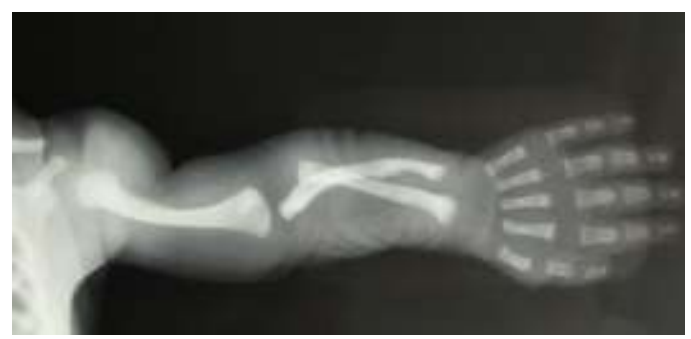

Figure 3: Bowed humerus, radius \& ulna

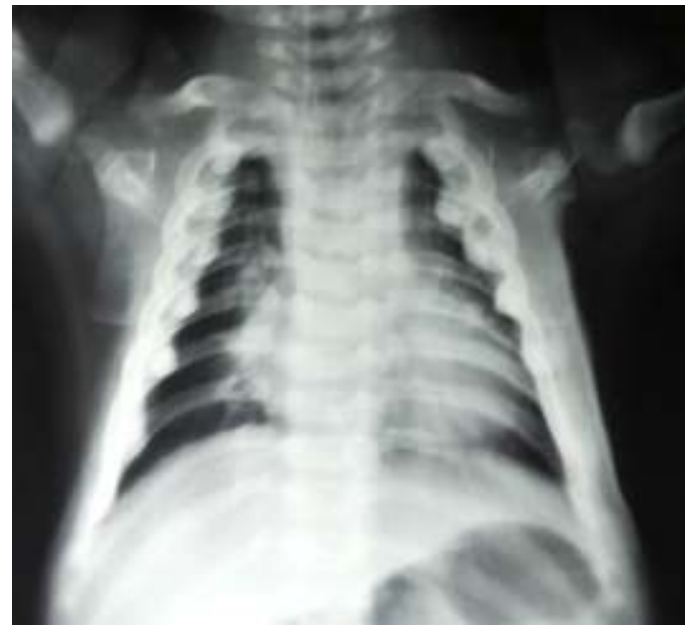

Figure 4: Deformed chest cavity 


\section{Discussion}

Campomelic dysplasia (CMD) is a rare autosomal dominant osteochondrodysplasia with or without sex reversal and with skeletal and non-skeletal defects, caused by de novo heterozygous mutations in the SOX9 gene (SRY-related HMG box gene family) on chromosome $17 \mathrm{q}^{1,2}$. The abnormal curvature of long bones, the main characteristic of $\mathrm{CMD}$, is absent in $10 \%$ of patients, and the disease is then called acampomelic campomelic dysplasia ${ }^{3}$. Muscular hypotonia, craniofacial dysmorphism, cleft palate, brachydactyly, malformations of thoracic spine, and gonadal dysgenesis with female external genitalia and müllerian duct derivatives in the presence of a male karyotype are the common features of $\mathrm{CMD}^{4}$. Pathological fracture is not uncommon in this disease ${ }^{4}$. Respiratory distress, caused by small thoracic cage and narrow airways from defective tracheobronchial cartilages, is the main cause of death, which occurs mostly in the neonatal period.

\section{References}

1. Hyoung-Young K, Chong Hyun Y, Gu-Hwan $\mathrm{K}$, et al. A case of campomelic dysplasia without sex reversal Journal of Korean Medical Science 2011; 26(1):143-5. http://dx.doi.org/10.3346/jkms.2011.26.1.143

2. Lefebvre V, Huang W, Harley VR, Goodfellow PN, de Crombrugghe B. SOXY is a potent activator of the chondrocyte-specific enhancer of the pro alpha1(II) collagen gene. Molecular and Cellular Biology 1997; 17: 2336-46.

3. Lecointre C, Pichon O, Hamel A et al: Familial acampomelic form of campomelic dysplasia caused by a $960 \mathrm{~kb}$ deletion upstream of SOX9. American Journal of Medical Genetics 2009; 149A: 1183-9. http://dx.doi.org/10.1002/ajmg.a.32830

4. Gimovsky M, Rosa E, Tolbert T. Campomelic dysplasia: case report and review. Journal of Perinatology 2008; 28:71-3.

http://dx.doi.org/10.1038/sj.jp.7211875 